\title{
Prediction of Propranolol Systemic Exposure Based on Heart-to-liver radioactivity uptake ratio and Laboratory Tests
}

\author{
Tae-Eun Kim ${ }^{1}$, Ju Seop Kang ${ }^{2}$, and Joo-Hyun Shon ${ }^{2}$ \\ ${ }^{1}$ Konkuk University Medical Center \\ ${ }^{2}$ Hanyang University College of Medicine
}

February 5, 2021

\begin{abstract}
BACKGROUND/AIM: Propranolol is a beta-adrenergic receptor blocker which is used for the treatment of portal hypertension in patients with liver cirrhosis. The systemic exposure of propranolol may vary according to the extent of portal hypertension and liver function. The objective of this study was to propose a model for predicting the exposure of propranolol. METHODS: Thirty normal subjects, 18 patients with chronic active hepatitis (CAH), and 54 patients with cirrhosis were included in this study. Blood samples for pharmacokinetic analysis were taken up to 8 hours post-dose. Pharmacokinetic analysis was performed using a non-compartmental model. The extent of portal hypertension was evaluated by heart-to-liver radioactivity uptake ratio (H/L ratio) using 201TI per rectal scintigraphy. A multivariate regression analysis was performed to determine the best model for estimating the Cmax or AUC of propranolol. RESULTS: Twenty-four normal subjects, 18 $\mathrm{CAH}$ patients, and 36 cirrhosis patients completed the study. A multivariate stepwise linear regression analysis revealed that sex, weight, total bilirubin concentrations, platelet counts, and H/L ratio affected the exposure of propranolol: Cmax $(\mathrm{ng} / \mathrm{mL})=50.976-18.743 \times \operatorname{sex}[\mathrm{M}: 1 ; \mathrm{F}: 0]-0.408 \times$ weight $+6.155 \times$ total bilirubin $+35.328 \times \mathrm{H} / \mathrm{L}$ ratio (adjusted r2=0.440); AUClast $(\mathrm{ng} \cdot \mathrm{h} / \mathrm{mL})=298.86-71.080 \times \operatorname{sex}[\mathrm{M}: 1 ; \mathrm{F}: 0]-2.158 \times$ weight $-0.312 \times$ platelet count $+26.372 \times$ total bilirubin $+176.745 \times \mathrm{H} / \mathrm{L} \mathrm{ratio}(\mathrm{ad}-$ justed $\mathrm{r} 2=0.500)$. CONCLUSION: A multivariate model based on laboratory tests, $\mathrm{H} / \mathrm{L}$ ratio, body weight, and sex can predict the systemic exposure of propranolol and thereby inform the prescription of propranolol in patients with liver disease.
\end{abstract}

Prediction of Propranolol Systemic Exposure Based on Heart-to-liver radioactivity uptake ratio and Laboratory Tests

Tae-Eun Kim¹, M.D., Ph.D., Ju-Seop Kang², M.D., Ph.D., Joo-Hyun Shon ${ }^{3}$, MD., PhD.

${ }^{1}$ Department of Clinical Pharmacology, Konkuk University Medical Center, Seoul, Republic of Korea (tekim@kuh.ac.kr)

${ }^{2}$ Department of Pharmacology \& Clinical Pharmacology Lab., College of Medicine, Hanyang University, Seoul, Republic of Korea (jskang@hanyang.ac.kr)

${ }^{3}$ Department of Internal Medicine(Gastroenterology), Hanyang University Guri Hospital, Kyeonggi-Do, Guri, Republic of Korea (sonjh@hanyang.ac.kr)

\section{Correspondence}

Ju-Seop Kang, M.D., Ph.D.,

Department of Pharmacology \& Clinical Pharmacology Lab., College of Medicine, Hanyang University, Seoul, 04763, Republic of Korea

E-mail: jskang@hanyang.ac.kr 
The authors confirm that the principal investigator for this paper is Joo-Hyun Shon and that he had direct clinical responsibility for patients.

Running headPrediction of propranolol systemic exposure

\section{Key words}

Propranolol, pharmacokinetics, liver cirrhosis, concentration

\section{Words count: 2042}

Table count: 3

\section{Figure count: 2}

\section{What is already known about this subject}

Propranolol is used for the treatment of portal hypertension and the prevention of resultant variceal bleeding in cirrhotic patients.

Portal hypertension occurred in cirrhotic patients reduces hepatic blood flow and increases the systemic exposure of propranolol by reducing metabolism. Thus, the systemic exposure of propranolol may vary according to the progression of liver cirrhosis.

Despite the possibility of varying pharmacokinetics according to the disease progression, only few small studies has been reported on the drug exposure or dose adjustment of propranolol in patients with liver cirrhosis.

\section{What this study adds}

We evaluated the pharmacokinetics of propranolol in 54 patients with cirrhosis, compared with 30 healthy individuals and 18 patients with chronic active hepatitis.

The systemic exposure of propranolol was affected by H/L ratio and several laboratory tests.

We proposed the prediction model for propranolol systemic exposure using those affecting elements.

\section{ABSTRACT}

BACKGROUND/AIM: Propranolol is a beta-adrenergic receptor blocker which is used for the treatment of portal hypertension in patients with liver cirrhosis. The systemic exposure of propranolol may vary according to the extent of portal hypertension and liver function. The objective of this study was to propose a model for predicting the exposure of propranolol.

METHODS: Thirty normal subjects, 18 patients with chronic active hepatitis (CAH), and 54 patients with cirrhosis were included in this study. Blood samples for pharmacokinetic analysis were taken up to 8 hours post-dose. Pharmacokinetic analysis was performed using a non-compartmental model. The extent of portal hypertension was evaluated by heart-to-liver radioactivity uptake ratio $\left(\mathrm{H} / \mathrm{L}\right.$ ratio) using $^{201} \mathrm{TI}$ per rectal scintigraphy. A multivariate regression analysis was performed to determine the best model for estimating the $\mathrm{C}_{\max }$ or $\mathrm{AUC}$ of propranolol.

RESULTS: Twenty-four normal subjects, $18 \mathrm{CAH}$ patients, and 36 cirrhosis patients completed the study. A multivariate stepwise linear regression analysis revealed that sex, weight, total bilirubin concentrations, platelet counts, and $\mathrm{H} / \mathrm{L}$ ratio affected the exposure of propranolol: $\mathrm{C}_{\max }(\mathrm{ng} / \mathrm{mL})=50.976-18.743 \times \operatorname{sex}[\mathrm{M}: 1 ; \mathrm{F}: 0]-$ $0.408 \times$ weight $+6.155 \times$ total bilirubin $+35.328 \times \mathrm{H} / \mathrm{L}$ ratio $\left(\right.$ adjusted $\left.\mathrm{r}^{2}=0.440\right) ; \mathrm{AUC}_{\text {last }}(\mathrm{ng} \cdot \mathrm{h} / \mathrm{mL})=298.86-$ $71.080 \times \operatorname{sex}[\mathrm{M}: 1 ; \mathrm{F}: 0]-2.158 \times$ weight $-0.312 \times$ platelet count $+26.372 \times$ total bilirubin $+176.745 \times \mathrm{H} / \mathrm{L}$ ratio (adjusted $\left.\mathrm{r}^{2}=0.500\right)$.

CONCLUSION: A multivariate model based on laboratory tests, $\mathrm{H} / \mathrm{L}$ ratio, body weight, and sex can predict the systemic exposure of propranolol and thereby inform the prescription of propranolol in patients with liver disease. 


\section{INTRODUCTION}

Propranolol is a nonselective beta-adrenergic receptor blocking agent. As blocking beta-adrenergic receptor sites induces reduction of inotropic and chronotropic response in heart and dilation of blood vessels, propranolol has been used for the treatment of hypertension, coronary artery disease, and atrial fibrillation.[1] Propranolol is also used to prevent variceal bleeding in cirrhotic patients. It manages portal hypertension by decreasing cardiac output and splanchnic blood flow, which lower the risk of variceal bleeding.[2, 3] As gastroesophageal varices are present in about $50 \%$ of all patients with cirrhosis, and are associated with high morbidity and mortality, all patients with cirrhosis should be evaluated for variceal bleeding. Guidelines recommend propranolol as a first-line medication for the primary or secondary prophylaxis of variceal bleeding. $[4,5]$

Propranolol is mainly eliminated by metabolism and cytochrome P450 (CYP) 2D6 and 1A2 primarily contribute to the metabolism. Because of its high extraction by the liver, a large proportion of propranolol is eliminated by pre-systemic metabolism and the bioavailability of propranolol is only 25\%.[1,6] The systemic exposure of high hepatic extraction drugs is influenced by hepatic blood flow, the fraction of protein binding, and hepatic intrinsic clearance. In patients with liver cirrhosis, the fraction of protein binding decreases because the production of albumin, which drugs bind to, is reduced and the function of hepatic enzymes which represents the intrinsic clearance decreases. Moreover, the portal hypertension reduces hepatic blood flow and increases bioavailability by reducing pre-systemic and systemic metabolism. [7, 8] Because of these pharmacokinetic changes, when propranolol is administered to prevent variceal bleeding, its systemic exposure may vary according to the extent of liver dysfunction and the extent of portal hypertension.

Despite the possibility of varying pharmacokinetics of propranolol according to the disease progression, there is little information available on the drug exposure or dose adjustment of propranolol in patients with liver cirrhosis. The guideline just recommends the dose adjusted based on the patient's blood pressure and heart rate. $[4,5]$

In this study, we investigate the factors that can affect the pharmacokinetics of propranolol including the extent of portal hypertension and propose a model that predicts the systemic exposure of propranolol.

\section{METHODS}

\section{Subjects \& study design}

This study was conducted with an open-label and parallel-study design. Clinical trials were conducted in Hanyang University Medical Center and the Institutional Review Board (IRB) of Hanyang University Medical Center approved the study protocol (IRB No. HYI-13-042-1). Informed consents were obtained from all subjects prior to study enrollment. All procedures were performed in accordance with the recommendations of the Declaration of Helsinki and the study was conducted in compliance with the current Good Clinical Practice.

A total of 102 subjects were included in this prospective study. Thirty subjects were normal subjects who did not have any marked medical history including liver cirrhosis. Eighteen subjects were patients with chronic active hepatitis $(\mathrm{CAH})$ and fifty-four subjects were patients with cirrhosis.

All the study subjects were administered $40 \mathrm{mg}$ of propranolol in fasting state. Blood samples $(8 \mathrm{~mL})$ for pharmacokinetic analysis were taken at pre-dose and $0.5,1,2,3,5$ and 8 hours post-dose.

${ }^{201} \mathrm{TI}$ per rectal scintigraphy and laboratory blood test were performed on separate days of pharmacokinetic study.

\section{Heart-to-liver radioactivity uptake ratio $(\mathrm{H} / \mathrm{L}$ ratio)}

Portal hypertension was evaluated by $\mathrm{H} / \mathrm{L}$ ratio using ${ }^{201} \mathrm{TI}$ per rectal scintigraphy. The measurement of $\mathrm{H} / \mathrm{L}$ ratio has been extensively described in previous papers $[9,10]$. Briefly, intrarectal administration of $18.5 \mathrm{MBq}$ of $^{201} \mathrm{Tl}$ was followed by acquisition of twenty-five 1-minute images of the cardiac and hepatic areas. When 
radioisotope activity showed a plateau, the ratio of radiation activity between the heart and liver area was acquired. The $\mathrm{H} / \mathrm{L}$ ratio was used as an indicator for the magnitude of portal hypertension.[11]

\section{Bioanalysis and pharmacokinetic analysis}

Plasma was obtained by centrifugation at 3,000 rpm for $10 \mathrm{~min}$ and stored in polypropylene tubes at $70{ }^{\circ} \mathrm{C}$ until concentrations were determined. Plasma concentrations of proparnolol and 4-OH-propranolol were determined with a validated liquid chromatography-tandem mass spectrometry (LC-MS/MS) method. The lower limit of quantification (LLOQ) for propranolol was $0.4 \mathrm{ng} / \mathrm{mL}$ with a linear calibration range of $0.4-100 \mathrm{ng} / \mathrm{mL}$ and that for 4-OH-propranolol was $0.3 \mathrm{ng} / \mathrm{mL}$ with a linear calibration range of $0.3-75$ $\mathrm{ng} / \mathrm{mL}$. Intra- and inter-day accuracies for propranolol were $90.5-104.0 \%$ and those for 4-OH-propranolol were 98.8-101.3\%; intra- and inter-day precisions varied with $<9.4 \mathrm{CV} \%$ for propranolol and $<6.67 \%$ for $4-\mathrm{OH}-$ propranolol. The peak plasma concentration $\left(\mathrm{C}_{\max }\right)$ and time to $\mathrm{C}_{\max }$ (i.e. $\mathrm{T}_{\max }$ ) were directly obtained from the observed values. The area under the concentration-time curve (AUC) from time 0 to the last measurable time $\left(\mathrm{AUC}_{\text {last }}\right)$ was calculated using the trapezoidal rule. The terminal half-life and AUC extrapolated to infinity $\left(\mathrm{AUC}_{\text {inf }}\right)$ were not determined because the pharmacokinetic blood samplings were not conducted until sufficient time after drug administration to evaluate elimination phase precisely. Non-compartmental analyses were performed using PK solutions pharmacokinetic software (SummitPK.com).

Statistical analysisDemographic characteristics and pharmacokinetic parameters were compared among the patient groups using the Kruskal-Wallis test. Post-hoc analysis was performed if there was a significant difference in the comparison of pharmacokinetic parameters. A multivariate regression with stepwise backward elimination was performed to determine the best model for predicting the $\mathrm{C}_{\max }$ or $\mathrm{AUC}_{\text {last }}$ of propranolol. The initial variables used in the multivariate regression were age, sex, body weight, clinical laboratory test results, and H/L ratio. IBM SPSS Statistics 21 (Datasolution Inc., version 21, Seoul, Korea) was used for statistical analysis. The two-sided level of statistical significance was set at 0.05 .

\section{RESULTS}

\section{Study population}

Of 102 subjects (30 normal subjects, 18 CAH patients and 54 cirrhosis patients), 78 subjects (24 normal subjects, $18 \mathrm{CAH}$ patients and 36 cirrhosis patients) completed the study. Of 36 cirrhosis patients, 34 were in Child-Pugh class A and 2 in class B. The mean ages of subjects who completed the study were 24.63 +- $6.04,46.56+-7.70$ and 54.72 +- 8.75 years in normal subjects, CAH patients and cirrhosis patients, respectively, showing significant difference. The heights, systolic blood pressures and heart rates were also significantly different among the groups. The baseline characteristics are presented in Table 1.

\section{Pharmacokinetics}

The propranolol plasma concentrations peaked at 2.0 hours in normal subjects, 1.9 hours in CAH patients, and 1.6 hours in cirrhotic patients, respectively, after drug administration (Figure 1). The $\mathrm{C}_{\max }$ and $\mathrm{AUC}_{\text {last }}$ of propranolol in patients with cirrhosis were higher than those in patients with CAH. However, there were no statistically significant differences between $\mathrm{CAH}$ patients and normal subjects or between cirrhosis patients and normal subjects in both $\mathrm{C}_{\max }$ and $\mathrm{AUC}_{\text {last }}$ of propranolol (Table 2). The plasma concentrations of 4-OHpropranolol, a major metabolite of propranolol, peaked at 1.3 hours in normal subjects, 1.3 hours in CAH patients, and 1.4 hours in cirrhotic patients, respectively (Figure 2). Consistent with the pharmacokinetics of propranolol, the $\mathrm{C}_{\max }$ and $\mathrm{AUC}_{\text {last }}$ of 4-OH-propranolol in patients with cirrhosis were significantly lower than those in patients with $\mathrm{CAH}$. However, there were no statistically significant differences between CAH patients and normal subjects or between cirrhosis patients and normal subjects in both $\mathrm{C}_{\max }$ and $\mathrm{AUC}_{\text {last }}$ of 4-OH-propranolol (Table 3).

\section{Prediction of systemic exposure}

A multivariate stepwise linear regression analysis revealed that sex, weight, total bilirubin, platelet count and $\mathrm{H} / \mathrm{L}$ ratio affected the exposure of propranolol. A subject with normal liver function was excluded 
in this model development due to his markedly high $\mathrm{C}_{\max }$ and $\mathrm{AUC}_{\text {last }}$ : $\mathrm{C}_{\text {max }}$ and $\mathrm{AUC}_{\text {last }}$ of that subject were higher than the mean $\mathrm{C}_{\max }$ and mean $\mathrm{AUC}_{\text {last }}$ of other normal subjects by 6.7 folds and 6.8 folds, respectively.

Male sex decreased both $\mathrm{C}_{\max }$ and $\mathrm{AUC}_{\text {last }}$ and the increase of weight also reduced both parameters. The $\mathrm{C}_{\max }$ and $\mathrm{AUC}_{\text {last }}$ were increased by $6.155 \mathrm{ng} / \mathrm{mL}$ and $26.372 \mathrm{ng} * \mathrm{~h} / \mathrm{mL}$, respectively for every $1 \mathrm{mg} / \mathrm{dL}$ increase in total bilirubin and they were increased by $35.328 \mathrm{ng} / \mathrm{mL}$ and $176.745 \mathrm{ng} * \mathrm{~h} / \mathrm{mL}$, respectively as $\mathrm{H} / \mathrm{L}$ ratio increase by 1 . Platelet count influenced on $\mathrm{AUC}_{\text {last }}$ but not on $\mathrm{C}_{\max }$. By the regression analysis, the equation that best predicts $\mathrm{C}_{\max }$ and $\mathrm{AUC}_{\text {last }}$ were as follows: $\mathrm{C}_{\max }(\mathrm{ng} / \mathrm{mL})=50.976-18.743 \mathrm{xsex}[\mathrm{M}: 1 ; \mathrm{F}: 0]$ -0.408 xweight $+6.155 x$ total bilirubin $+35.328 \mathrm{xH} / \mathrm{L}$ ratio (adjusted $\left.\mathrm{r}^{2}=0.440\right), \mathrm{AUC}_{\text {last }}(\mathrm{ng} * \mathrm{~h} / \mathrm{mL})=298.86$ - 71.080xsex[M:1;F:0] - 2.158xweight $-0.312 x p l a t e l e t$ count $+26.372 x$ total bilirubin $+176.745 \mathrm{xH} / \mathrm{L}$ ratio (adjusted $\mathrm{r}^{2}=0.500$ ).

\section{DISCUSSION}

In this study, we investigated the pharmacokinetics of propranolol in patients with liver cirrhosis, and in healthy individuals and patients with chronic active hepatitis. We also identified the clinical factors that affect pharmacokinetics of propranolol and suggested a model for prediction of systemic exposure of propranolol. Generally, the bioavailability of a drug with high hepatic extraction is influenced by hepatic blood flow, protein binding, and intrinsic clearance; and the elimination is determined mainly by hepatic blood flow.[7] As propranolol is a typical drug with high hepatic extraction, the reduction of hepatic blood flow by portal hypertension can have a critical effect on the systemic exposure of propranolol by both increasing bioavailability and reducing elimination.

A few small studies have evaluated the pharmacokinetics of propranolol in normal subjects and patients with cirrhosis. A study with 6 normal subjects and 6 cirrhotic patients showed that the AUC during a dosing interval $(\mathrm{AUC} \tau)$ was 3.5 times higher in cirrhotic patients after the administration of $80 \mathrm{mg}$ of propranolol twice a day for 7 days.[12] In another study involving 5 normal subjects and 15 cirrhotic patients, AUC $_{\text {inf }}$ in cirrhotic patients was about 5 times higher than in normal subject after the single administration of $40 \mathrm{mg}$ of propranolol.[13] In this study, the mean $\mathrm{C}_{\max }$ and $\mathrm{AUC}_{\text {last }}$ in patients with liver cirrhosis were higher by 1.2 folds and 1.4 folds compared to normal subjects, however, there was no statistically significant difference. The increase of systemic exposure in cirrhotic patients were obviously low comparing to previous studies. This small increase can be because most patients with cirrhosis were in Child-Pugh class A. In this study, the pharmacokinetics of propranolol were also evaluated in the patients with $\mathrm{CAH}$. The patients with CAH exhibited the lowest systemic exposure of propranolol among three groups. While the protein binding and intrinsic clearance were comparable to those in normal subjects, the hepatic blood flow increased due to inflammation in these patients, which presumably increased hepatic elimination.

The $\mathrm{C}_{\max }$ and $\mathrm{AUC}_{\text {last }}$ of propranolol were predicted by sex, weight, total bilirubin level, platelet count $\left(\mathrm{AUC}_{\text {last }}\right.$ only) and $\mathrm{H} / \mathrm{L}$ ratio using the regression model. Weight can naturally influence drug systemic exposure and total bilirubin level and platelet count are considered to represent the liver function being related to intrinsic hepatic clearance and plasma protein binding. Interestingly, sex was a prediction factor for both $\mathrm{C}_{\max }$ and $\mathrm{AUC}_{\text {last }}$. Several studies reported that the sex difference in pharmacokinetics of propranolol.[14-16] These studies have commonly reported that the clearance of propranolol in male was higher. The authors suggested that circulating gonadal hormones might influence propranolol metabolism. Our finding is consistent with these previous reports.

A total of 78 subjects including 36 of cirrhotic patients, 18 of CAH patients and 24 of normal subjects were completed this study. Not only the number of subjects was large compared to previous studies, but this study evaluated $\mathrm{H} / \mathrm{L}$ ratio representing portal hypertension. To the best of our knowledge, it is the first study that the measurement of portal hypertension was used for the prediction of pharmacokinetics. The extent of portal hypertension was found to significantly influence the systemic exposure of propranolol. The developed prediction model is expected to be applied to the pharmacokinetic prediction of drugs which is mainly eliminated by metabolism and have high hepatic extraction. 
Despite these positive aspects of the present study, there were some limitations that should be addressed. The important one is the limitation of disease status of patients with cirrhosis. Most patients with cirrhosis were in Child-Pugh class A except for 2 patients who were in class B. For this limitation, it is not certain that our proposed model can be applied to patients with advanced chronic liver disease. In addition, our prediction model can only be applied to a drug of high hepatic extraction, because the influencing factors on the pharmacokinetics of low hepatic extraction drugs are different from those of high hepatic extraction drugs.

\section{CONCLUSION}

We report a mathematical model based on laboratory tests, H/L ratio, body weight and sex that can help predict the systemic exposure of propranolol. This model can inform optimal prescription of propranolol in patients with liver cirrhosis who are at increased risk of variceal bleeding.

\section{Figure legends}

Figure 1. Plasma concentration-time profile of propranolol

Figure 2. Plasma concentration-time profile of 4-OH-propranolol

\section{Acknowledgement}

This work was supported by the Korea government (The Ministry of Food and Drug Safety/National Institute of Food and Drug Safety Evaluation) (Project Number: 13182imsangpyeong701)

\section{Funding}

This work was supported by the Korea government (The Ministry of Food and Drug Safety/National Institute of Food and Drug Safety Evaluation) (Project Number: 13182imsangpyeong701)

\section{Author contribution}

Ju-Seop Kang conceived and planned present study. Joo-Hyun Shon carried out the clinical trial and collected data. Tae-Eun Kim analyzed the data and discussed the result with Ju-Seop Kang and Joo-Hyun Shon. Tae-Eun Kim wrote the manuscript. All the authors contributed to the final version of the manuscript.

\section{Conflict of interest}

There are no conflicts of interest in connection with this article.

\section{References}

1. "Inderal@ (Propranolol) [Package Insert]. U.S. Food and Drug Administration. Wyeth Pharmaceuticals, Inc. Available From: Https://Www.Accessdata.Fda.Gov/Drugsatfda_Docs/Label/2011/016418s080,016762s017,017683s008lbl.Pdf. Accessed August 19, 2020.".

2. Groszmann, R.J.;Garcia-Tsao, G.;Bosch, J.;Grace, N.D.;Burroughs, A.K.;Planas, R.;Escorsell, A.;GarciaPagan, J.C.;Patch, D.;Matloff, D.S., et al. "Beta-Blockers to Prevent Gastroesophageal Varices in Patients with Cirrhosis." N Engl J Med 353, no. 21 (2005): 2254-61.

3. Kroeger, R.J.;Groszmann, R.J. "Increased Portal Venous Resistance Hinders Portal Pressure Reduction During the Administration of Beta-Adrenergic Blocking Agents in a Portal Hypertensive Model." Hepatology 5, no. 1 (1985): 97-101.

4. Haq, I.;Tripathi, D. "Recent Advances in the Management of Variceal Bleeding." Gastroenterol Rep (Oxf) 5, no. 2 (2017): 113-26.

5. Jalan, R.;Hayes, P.C. "Uk Guidelines on the Management of Variceal Haemorrhage in Cirrhotic Patients. British Society of Gastroenterology." Gut 46 Suppl 3-4 (2000): III1-III15.

6. Nies, A.S.;Shand, D.G. "Clinical Pharmacology of Propranolol." Circulation 52, no. 1 (1975): 6-15. 
7. Rowland, M.;Tozer, T.N. Clinical Pharmacokinetics Concepts and Application. . 4th ed: Lippincott Williams\&Wilkins, 4th edition, 2010.

8. Delco, F.;Tchambaz, L.;Schlienger, R.;Drewe, J.;Krahenbuhl, S. "Dose Adjustment in Patients with Liver Disease." Drug Saf 28, no. 6 (2005): 529-45.

9. Tonami, N.;Nakajima, K.;Hisada, K.;Tanaka, N.;Kobayashi, K. "A Noninvasive Method for Evaluating Portal Circulation by Administration of Ti-201 Per Rectum." J Nucl Med 23, no. 11 (1982): 965-72.

10. D’Arienzo, A.;Celentano, L.;Scuotto, A.;Di Siervi, P.;Lombardi, V.;Squame, G.;Mazzacca, G. "Thallium201 Per Rectum for the Diagnosis of Cirrhosis in Patients with Asymptomatic Chronic Hepatitis." Hepatology 8, no. 4 (1988): 785-7.

11. Lee, M.H.;Tae, H.J.;Jun, D.W.;Ryu, S.E.;Choi, Y.Y.;Kwak, M.J.;Kang, J.S. "201tl Heart-Liver Radioactivity Uptake Ratio and Prediction of Decompensation in Patients with Cirrhosis." Clin Nucl Med 38, no. 3 (2013): 169-74.

12. Watson, R.G.;Bastain, W.;Larkin, K.A.;Hayes, J.R.;McAinsh, J.A.;Shanks, R.G. "A Comparative Pharmacokinetic Study of Conventional Propranolol and Long Acting Preparation of Propranolol in Patients with Cirrhosis and Normal Controls." Br J Clin Pharmacol 24, no. 4 (1987): 527-35.

13. Taegtmeyer, A.B.;Haschke, M.;Tchambaz, L.;Buylaert, M.;Tschopl, M.;Beuers, U.;Drewe, J.;Krahenbuhl, S. "A Study of the Relationship between Serum Bile Acids and Propranolol Pharmacokinetics and Pharmacodynamics in Patients with Liver Cirrhosis and in Healthy Controls." PLoS One 9, no. 6 (2014): e97885.

14. Xie, H.G.;Chen, X. "Sex Differences in Pharmacokinetics of Oral Propranolol in Healthy Chinese Volunteers." Zhongguo Yao Li Xue Bao 16, no. 5 (1995): 468-70.

15. Walle, T.;Walle, U.K.;Cowart, T.D.;Conradi, E.C. "Pathway-Selective Sex Differences in the Metabolic Clearance of Propranolol in Human Subjects." Clin Pharmacol Ther 46, no. 3 (1989): 257-63.

16. Walle, T.;Walle, K.;Mathur, R.S.;Palesch, Y.Y.;Conradi, E.C. "Propranolol Metabolism in Normal Subjects: Association with Sex Steroid Hormones." Clin Pharmacol Ther 56, no. 2 (1994): 127-32.

Table 1. Demographic data of the subjects who completed study

\begin{tabular}{lllll}
\hline Parameters & Normal $(\mathrm{N}=24)$ & CAH $(\mathrm{N}=18)$ & Cirrhosis $(\mathrm{N}=36)$ & P-value \\
\hline Male sex $(\%)$ & $17(70.8 \%)$ & $11(61.1 \%)$ & $20(55.6 \%)$ & 0.491 \\
Age (year) & $24.71 \pm 6.50$ & $46.56 \pm 7.70$ & $53.89 \pm 9.03$ & $<0.001$ \\
Height (cm) & $170.61 \pm 8.49$ & $162.56 \pm 6.6$ & $163.32 \pm 9.44$ & 0.003 \\
$\begin{array}{l}\text { Weight (kg) } \\
\text { Systolic BP }\end{array}$ & $62.86 \pm 9.15$ & $64.44 \pm 7.48$ & $64.03 \pm 12.79$ & 0.876 \\
$\begin{array}{l}\text { (mmHg) } \\
\text { Diastolic BP }\end{array}$ & $116.00 \pm 9.85$ & $123.00 \pm 9.83$ & $124.11 \pm 13.54$ & 0.030 \\
$\begin{array}{l}\text { (mmHg) } \\
\begin{array}{l}\text { Heart rate } \\
\text { (beat/min) }\end{array}\end{array}$ & $74.83 \pm 8.86$ & $77.06 \pm 7.94$ & $76.72 \pm 9.61$ & 0.661 \\
\hline
\end{tabular}

Table 2. Pharmacokinetic parameters of propranolol by subject group

\begin{tabular}{llllllll}
\hline & & & & & P-values \\
Parameters & Normal & CAH & Cirrhosis & P-values & $\begin{array}{l}\text { P-values } \\
\text { (post-hoc } \\
\text { (post-hoc } \\
\text { analysis) }\end{array}$ \\
\hline
\end{tabular}




\begin{tabular}{llllllll}
\hline & $\begin{array}{l}\text { Normal } \\
(\mathrm{N}=24)\end{array}$ & $\begin{array}{l}\mathrm{CAH} \\
(\mathrm{N}=18)\end{array}$ & $\begin{array}{l}\text { Cirrhosis } \\
(\mathrm{N}=36)\end{array}$ & P-value & $\begin{array}{l}\text { P-values } \\
\text { (post-hoc } \\
\text { analysis) }\end{array}$ & $\begin{array}{l}\text { P-values } \\
\text { (post-hoc } \\
\text { analysis) }\end{array}$ & $\begin{array}{l}\text { P-values } \\
\text { (post-hoc } \\
\text { analysis) }\end{array}$ \\
\hline $\begin{array}{l}\text { Aurameters } \\
(\mathrm{ng} \cdot \mathrm{h} / \mathrm{mL})\end{array}$ & $150.2 \pm 154.1$ & $112.2 \pm 84.7$ & $204.0 \pm 137.3$ & 0.018 & 1.000 & 0.170 & 0.024 \\
$\begin{array}{l}\mathrm{C}_{\max } \\
(\mathrm{ng} / \mathrm{mL})\end{array}$ & $33.6 \pm 34.8$ & $23.7 \pm 18.2$ & $41.2 \pm 27.9$ & 0.040 & 0.844 & 0.464 & 0.041 \\
$\mathrm{~T}_{\max }(\mathrm{h})$ & $1.96 \pm 0.81$ & $1.89 \pm 0.96$ & $1.58 \pm 0.95$ & 0.098 & - & - & - \\
\hline
\end{tabular}

Table 3. Pharmacokinetic parameters of 4-OH-propranolol by subject group

\begin{tabular}{llllllll}
\hline & $\begin{array}{l}\text { Normal } \\
(\mathrm{N}=24)\end{array}$ & $\begin{array}{l}\mathrm{CAH} \\
(\mathrm{N}=18)\end{array}$ & $\begin{array}{l}\text { Cirrhosis } \\
(\mathrm{N}=36)\end{array}$ & P-value & $\begin{array}{l}\text { P-values } \\
\text { (post-hoc } \\
\text { analysis) }\end{array}$ & $\begin{array}{l}\text { P-values } \\
\text { (post-hoc } \\
\text { analysis) }\end{array}$ & $\begin{array}{l}\text { P-values } \\
\text { (post-hoc } \\
\text { analysis) }\end{array}$ \\
\hline & & & & $\begin{array}{l}\text { Normal- } \\
\text { CAH }\end{array}$ & $\begin{array}{l}\text { Normal- } \\
\text { Cirrhosis }\end{array}$ & $\begin{array}{l}\text { CAH- } \\
\text { Cirrhosis }\end{array}$ \\
$\begin{array}{l}\text { AUC } \\
(\mathrm{ng} \cdot \mathrm{h} / \mathrm{mL})\end{array}$ & $14.5 \pm 6.9$ & $19.8 \pm 12.9$ & $12.6 \pm 11.0$ & 0.007 & 0.584 & 0.218 & 0.007 \\
$\begin{array}{l}\mathrm{C}_{\max } \\
(\mathrm{ng} / \mathrm{mL})\end{array}$ & $6.1 \pm 3.8$ & $7.4 \pm 4.7$ & $5.0 \pm 5.4$ & 0.010 & 1.000 & 0.134 & 0.014 \\
$\mathrm{~T}_{\max }(\mathrm{h})$ & $1.29 \pm 0.46$ & $1.33 \pm 0.59$ & $1.40 \pm 0.88$ & 0.979 & - & - & - \\
\hline
\end{tabular}

Figure 1. Plasma concentration-time profile of propranolol

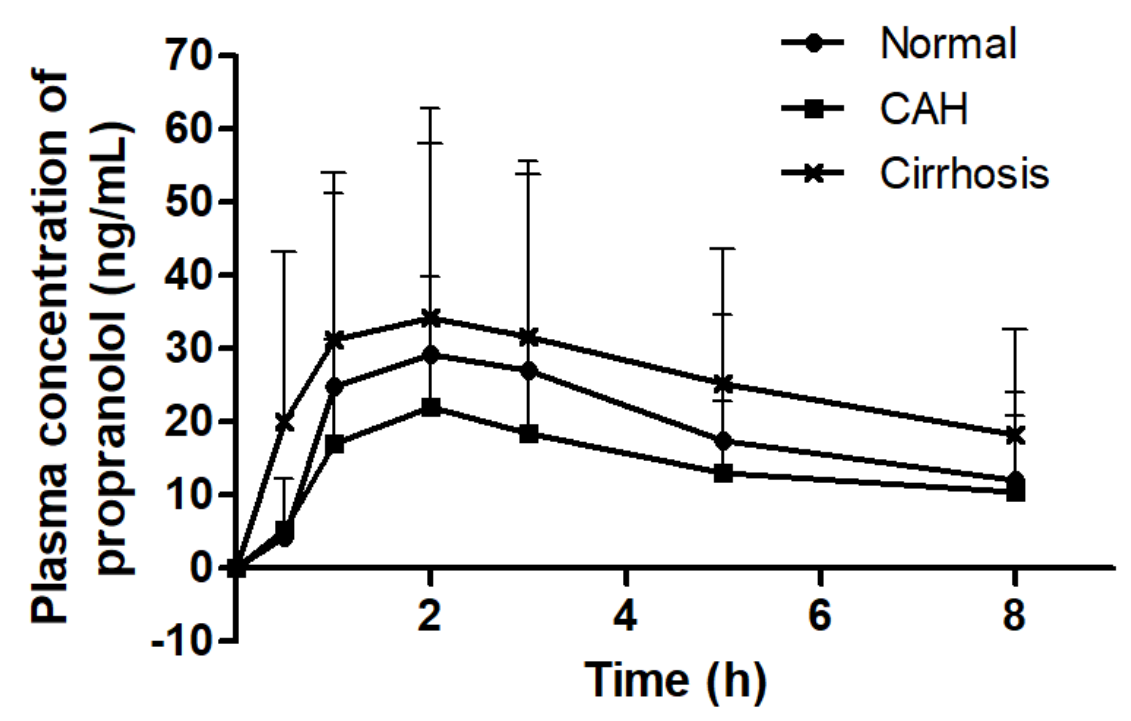

Figure 2. Plasma concentration-time profile of 4-OH-propranolol 


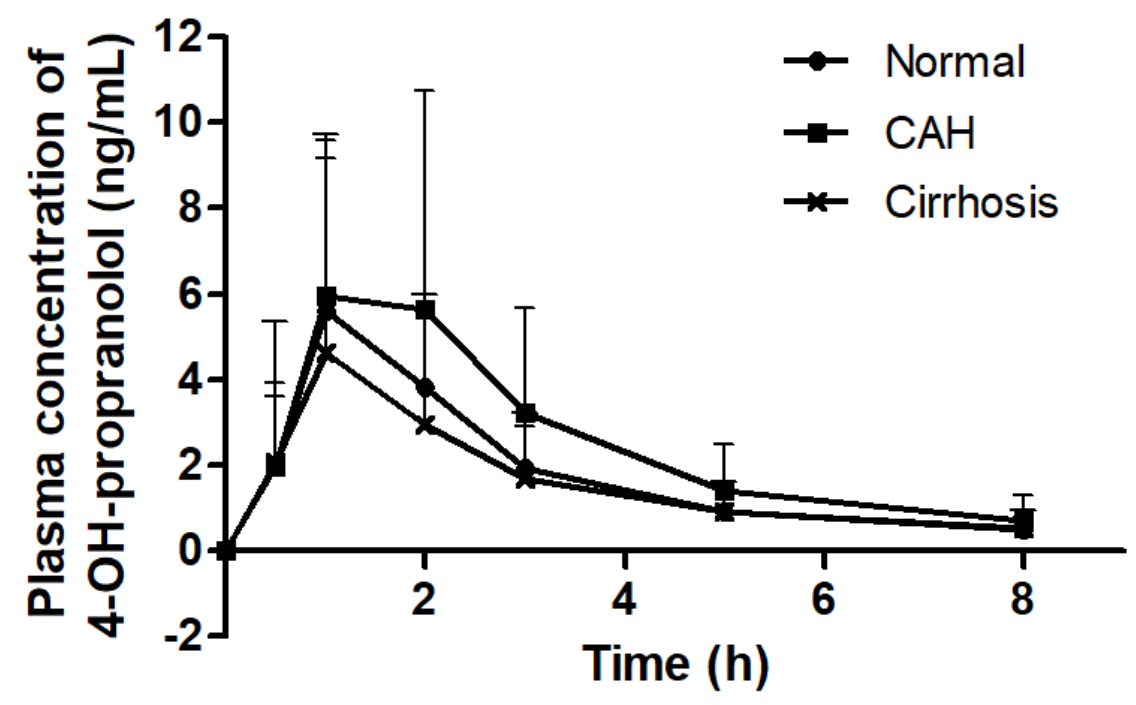

